\title{
Frutos do umbuzeiro armazenados sob atmosfera modificada e ambiente em diferentes estádios de maturação ${ }^{1}$
}

\author{
Umbu tree fruit stored under modified and ambient atmospheric conditions at \\ different maturity stages
}

\author{
Fabiano Tavares de Moura ${ }^{2}$, Silvanda de Melo Silva*, Ana Paula Pereira Schunemann e Laesio Pereira \\ Martins $^{2}$
}

\begin{abstract}
RESUMO - O objetivo do trabalho foi avaliar a qualidade de frutos do umbuzeiro em três estádios de maturação e armazenados sob atmosferas modificada (AM) e em condição ambiente (AA). O delineamento utilizado foi o inteiramente casualizado em esquema fatorial $2 \times 3 \times 6$, sendo duas atmosferas de armazenamento (AA e AM), três estádios de maturação: 'verde', 'verde-maduro' e 'maduro', e seis períodos de armazenamento a $23 \pm 1{ }^{\circ} \mathrm{C}$ e $83 \pm 2 \%$ UR. As avaliações realizadas foram sólidos solúveis (SS), acidez titulável (AT), relação SS/AT, perda de massa, coloração da casca e aparência geral. Os SS de umbus mantidos sob AA foram mais elevados que os sob AM, sendo os menores teores os de frutos do estádio verde. A vida útil de umbu colhido maduro e mantido sob AA foi limitada a três dias, devido à excessiva perda de massa. O emprego da AM foi o fator determinante na manutenção da qualidade do umbu armazenado sob a condição ambiente por reduzir a perda de massa, manter a aparência atrativa, permitir a evolução da coloração para a amarela mais intensa, proporcionando um incremento na vida útil aos frutos colhidos verde e 'verde-maduro' em dois e um dia, respectivamente.
\end{abstract}

Palavras-chave: Spondias tuberosa. Aparência. Evolução da coloração. Conservação pós-colheita.

\begin{abstract}
The objective of this study was to evaluate the quality of fruits of the Brazil Plum at three stages of maturation, when stored under conditions of modified (MA) and ambient (AA) atmospheric conditions. The experimental design used was a completely randomized $2 \times 3 \times 6$ factorial scheme of two storage atmospheres (AA and MA), three stages of maturation ('green', 'turning' and 'mature'), and six storage periods at $23 \pm 1{ }^{\circ} \mathrm{C}$ and $83 \pm 2 \% \mathrm{RH}$. The evaluations carried out were for soluble solids (SS), titratable acidity (TA), the SS/TA ratio, weight loss, skin color and general appearance. The SS of Brazil Plum kept under AA were higher than those under MA, with the lowest levels being from the green fruit. The shelf life of the Brazil Plum, harvested when mature and kept under AA, was limited to three days due to excessive weight loss. The use of MA was the determining factor in maintaining the quality of the Brazil Plum stored under ambient conditions by reducing weight loss, keeping its attractive appearance, allowing the color to develop into a deeper yellow, and providing an increase in shelf life for those fruits harvested when green or turning of two and one days respectively.
\end{abstract}

Key words: Spondias tuberosa. Appearance. Evolution of coloration. Postharvest conservation.

\footnotetext{
*Autor para correspondência

${ }^{1}$ Recebido para publicação em 03/06/2012; aprovado em 04/04/2013

Pesquisa realizada com suporte financeiro do CNPq e CAPES/PNPD

${ }^{2}$ Centro de Ciências Humanas Sociais e Agrárias, Universidade Federal da Paraíba/UFPB, Bananeiras-PB, Brasil, fabianotmoura@yahoo.com.br, laesiopm@gmail.com.br

3Programa de Pós-Graduação em Agronomia, Centro de Ciências Agrárias/Universidade Federal da Paraíba/UFPB, Areia-PB, Brasil, silvasil@ cca.ufpb.br, anaschunemann@gmail.com.br
} 


\section{INTRODUÇÃO}

O umbuzeiro (Spondias tuberosa Arr. Cam.) é uma frutífera tropical originária dos chapadões semiáridos do Nordeste brasileiro, ocorrendo de forma espontânea e com elevada diversidade genética nas regiões do Agreste (Piauí), Cariris(Paraíba), Caatinga(PernambucoeBahia)(SANTOS; RODRIGUES; ZUCCHI, 2008), sendo consideravelmente importante a safra na geração de emprego e renda para a população do Semiárido (DUQUE, 2004).

De acordo com o INSTITUTO BRASILEIRO DE GEOGRAFIA E ESTATÍSTICA (2012), foram extraídas 9.804 toneladas de umbu no Brasil em 2010, sendo que a participação da produção baiana foi de $89 \%$ (TURINI, 2010). Na época da safra, dezembro a março, dependendo da região de ocorrência, há grande oferta de umbu, pela exploração extrativista, para consumo fresco (SANTOS; RODRIGUES; ZUCCHI, 2008; SILVA et al., 2011) ou industrialização (TURINI, 2010). Entretanto, a maioria dos estudos é voltada para a avaliação de produtos processados, como polpa congelada, sorvete, geleia e/ou doces (BORGES et al., 2011).

Atualmente os frutos do umbuzeiro têm ganhado espaço nos mercados nacional e internacional, pois, além de apresentarem sabor agradável e aroma peculiar, são uma boa fonte de compostos bioativos e seu consumo pode contribuir substancialmente na dieta (ALMEIDA et al., 2011; RUFINO et al., 2010; SILVA et al., 2012; TIBURSKI et al., 2011). Entretanto, devido à sua elevada perecibilidade (MOURA et al., 2003), o fruto é raramente consumido fresco em outras regiões do Brasil (DANTAS JUNIOR, 2008; TURINI, 2010). Portanto, torna-se importante que estudos mais aprofundados sobre a qualidade sejam realizados, sobretudo quanto à maturidade na colheita e estratégias tecnológicas acessíveis para a manutenção da qualidade pós-colheita sob a condição ambiente, atualmente sua principal forma de comercialização (ALVES et al., 2008). Dessa forma, o desenvolvimento de tecnologias visando estabelecer condições que retardem o amadurecimento e a senescência, mantendo a qualidade e prolongando a vida útil durante $\mathrm{o}$ armazenamento do umbu é necessário, tendo em vista o potencial socioeconômico desse fruto.

A manutenção da qualidade pós-colheita está relacionada com a minimização da taxa de deterioração, ou seja, mantê-los atrativos ao consumidor por um período de tempo mais prolongado (PALIYATH et al., 2008). O uso de atmosfera modificada (AM) tem se mostrado eficiente em reduzir as taxas metabólicas ampliando a vida útil de frutos de umbuzeiro (LOPES, 2007). O emprego de AM, pelo uso de filmes flexíveis, como o de cloreto de polivinila (PVC), estabelece uma composição gasosa no interior da embalagem diferente da do ar, pela redução da concentração de $\mathrm{O}_{2}$ e elevação do $\mathrm{CO}_{2}$, que pode reduzir as taxas de respiração e produção de etileno, promovendo um retardamento da senescência desses produtos (KADER, 2010).

Além disso, a colheita dos frutos em estádios adequados de maturação é determinante na manutenção da qualidade pós-colheita. O estádio de maturação de colheita mais adequado depende da interação das características fisiológicas intrínsecas a cada variedade e da tecnologia de conservação pós-colheita a ser empregada (KAFKAS et al., 2007; SANTOS et al., 2006).

Diante do exposto, o objetivo foi avaliar a qualidade pós-colheita de frutos do umbuzeiro colhidos em diferentes estádios de maturação e armazenados sob atmosferas modificada e ambiente.

\section{MATERIAL E MÉTODOS}

Frutos do umbuzeiro foram colhidos de doze plantas previamente identificadas e georreferenciadas de propriedade localizada no município de Barra de Santa Rosa (latitude: 06 43 '11" S, longitude: 36 03 '38' W, altitude: $457 \mathrm{~m}$ ), microrregião do Curimataú Paraibano, em abril de 2011.

Os frutos foram colhidos manualmente, no mesmo período da manhã, por toda extensão das copas e selecionados visualmente quanto à maturidade tomando-se como base a coloração da casca e a firmeza aparente, sendo classificados nos estádios de maturação 'verdes', 'verdemaduros' e 'maduros'. As avaliações foram realizadas no Laboratório de Biologia e Tecnologia Pós-Colheita do Centro de Ciências Agrárias da Universidade Federal da Paraíba (UFPB-CCA). Os frutos foram selecionados considerando o estádio de maturação, uniformidade de tamanho e a ausência de danos mecânicos ou doenças. Em seguida, os frutos foram lavados em água corrente e, como tratamento antifúngico, imersos em solução de hipoclorito de sódio comercial a $200 \mu \mathrm{L} \mathrm{L}^{-1}$, seguido de remoção do excesso de água com auxílio de ventilador.

Foi utilizado o delineamento inteiramente casualizado, com 4 repetições, 36 frutos por unidade experimental, em esquema fatorial $2 \times 3 \times 7$, sendo duas atmosferas de armazenamento (atmosfera ambiente - AA e modificada AM) sob temperatura de $23 \pm 1^{\circ} \mathrm{Ce} 83 \pm 2 \%$ UR, três estádios de maturação: verde, 'verde-maduro' e maduro, durante seis períodos de armazenamento: $0 ; 1 ; 2 ; 3 ; 4 ; 5$ e 6 dias.

Os frutos foram embalados em bandejas de poliestireno expandido com dimensões de 210 x 140 x 10 (mm) e, para a modificação da atmosfera, as bandejas foram envolvidas com filme de cloreto de polivinila (PVC) flexível de $14 \mu \mathrm{m}$ de espessura. 
Foram avaliados: Sólidos solúveis (SS - \%); acidez titulável (AT - \% de ácido cítrico); relação SS/AT (INSTITUTO ADOLFO LUTZ, 2008). Perda de massa calculada tomando-se como referência a massa inicial dos frutos, usando-se balança semi-analítica; aparência geral (sendo relevante a incidência de infestações fúngicas e senescência) foi realizada por 12 avaliadores treinados, mediante escala cujas notas variavam de 1-9, onde 1 (inaceitável), 3 (ruim), 5 (regular), 7 (bom), 9 (excelente), sendo o escore 5 correspondente ao limite em que a aparência limitava a aceitação do produto pelo consumidor. A coloração da casca avaliada com auxílio de um colorímetro digital Minolta (CR-300), o qual expressa a cor em parâmetros: L* (corresponde à claridade/luminosidade); $a^{*}$ (define a transição da cor verde $\left(-a^{*}\right)$ para a cor vermelha $\left(+a^{*}\right)$ e $b^{*}$ (representa a transição da cor azul $\left(-b^{*}\right)$ para a cor amarela $\left(+b^{*}\right)$.

Os dados foram submetidos à análise de variância (ANOVA), considerando os efeitos das interações entre os fatores, everificando-se oefeito significativodas interações, o período foi desdobrado dentro de cada tratamento e os resultados submetidos à análise de regressão polinomial. Quando não constatado efeito significativo entre as interações dos fatores avaliados, foi realizado ligação de pontos com as médias dos tratamentos. Os modelos de regressão polinomiais foram selecionados com base na significância do teste $\mathrm{F}$ de cada modelo testado e, também, pelo coeficiente de determinação.

\section{RESULTADOS E DISCUSSÃO}

Observa-se na Figura 1 que houve interação significativa para os fatores atmosfera, período de armazenamento e estádio de maturação nas características: Sólidos Solúveis (SS), Acidez Titulável (AT), SS/AT, ácido ascórbico e na Luminosidade $\left(L^{*}\right)$.
Os frutos mantidos sob AA tiveram os teores de SS mais elevados que os mantidos sob AM, $\mathrm{p} \leq 0,05$ (Figura 1). Lopes (2007) comparando atmosferas ambiente (AA) e modificada (AM) em umbu-laranja maduros também observou maiores teores de SS em AA.

Os SS foram mais baixos em umbus do estádio verde, tanto em AA quanto em AM. Campos (2007) avaliando frutos de umbuzeiro em cinco estágios de desenvolvimento observaram maior teor de sólidos solúveis à medida que os frutos avançavam a maturação, onde o maior conteúdo foi de $12,3 \%$ no fruto considerado maduro.

Nos estádios 'verde-maduro' e 'maduro', foram observadas pequenas oscilações durante os dias de armazenamento.Apartirdoprimeiro diade armazenamento, ocorreu uma elevação nos teores de SS nos frutos sob AM (Figura 1A), com posterior decréscimo no decorrer dos períodos avaliados com tendência a se aproximar aos valores iniciais. Os estádios "verde-maduro" e 'maduro', em AM (Figura 1B) tiveram comportamento semelhante para a concentração de SS até o $5^{\circ}$ dia de armazenamento. Estes valores são próximos aos encontrados por Santos et al. (2010), que observou $10 \%$ de SS em frutos maduros de umbu e umbu-cajá, respectivamente.

De modo geral, a AT aumentou significativamente ao longo do período de armazenamento, tanto para os frutos em Atmosfera Ambiente (Figura 2A) quanto em Modificada (Figura 2B).

Observou-se que a atmosfera de armazenamento não influenciou significativamente sobre a acidez total nos estádios de maturação 'verde-maduro' e 'maduro'. Os frutos no estádio verde mantidos sob AA (Figura 2A) apresentaram um aumento gradativo em relação aos mantidos sob AM (Figura 2B) e, quando comparados aos estádios de maturação ‘verde-maduro' e 'maduro'. Lopes (2007), em estudo com frutos de umbu-laranja 'maduros'

Figura 1 - Sólidos solúveis de frutos do umbuzeiro nos estádios 'verde', 'verde-maduro' e 'maduro', durante seis dias de armazenamento a $23 \pm 1{ }^{\circ} \mathrm{C}$ e $83 \pm 2 \%$ UR, sob atmosferas ambiente (1A) e modificada (1B)

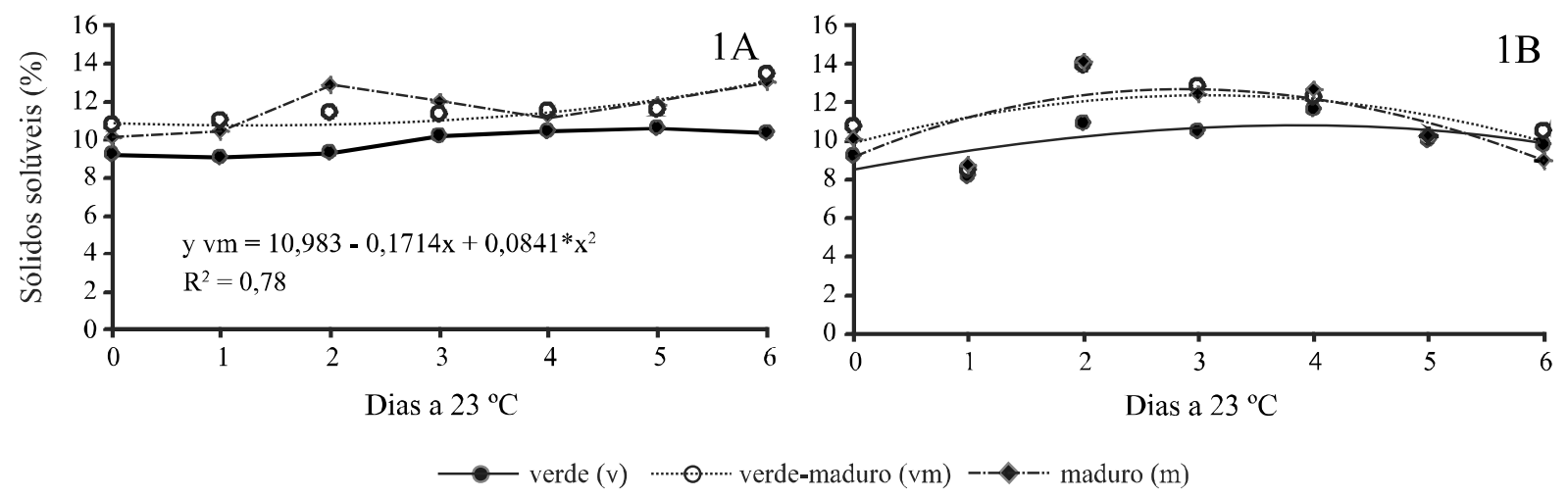


Figura 2 - Acidez titulável (AT) em frutos do umbuzeiro nos estádios de maturação 'verde', 'verde-maduro' e 'maduro', durante seis dias de armazenamento a $23 \pm 1{ }^{\circ} \mathrm{C}$ e $83 \pm 2 \%$ UR, sob atmosferas ambiente (2A) e modificada (2B)

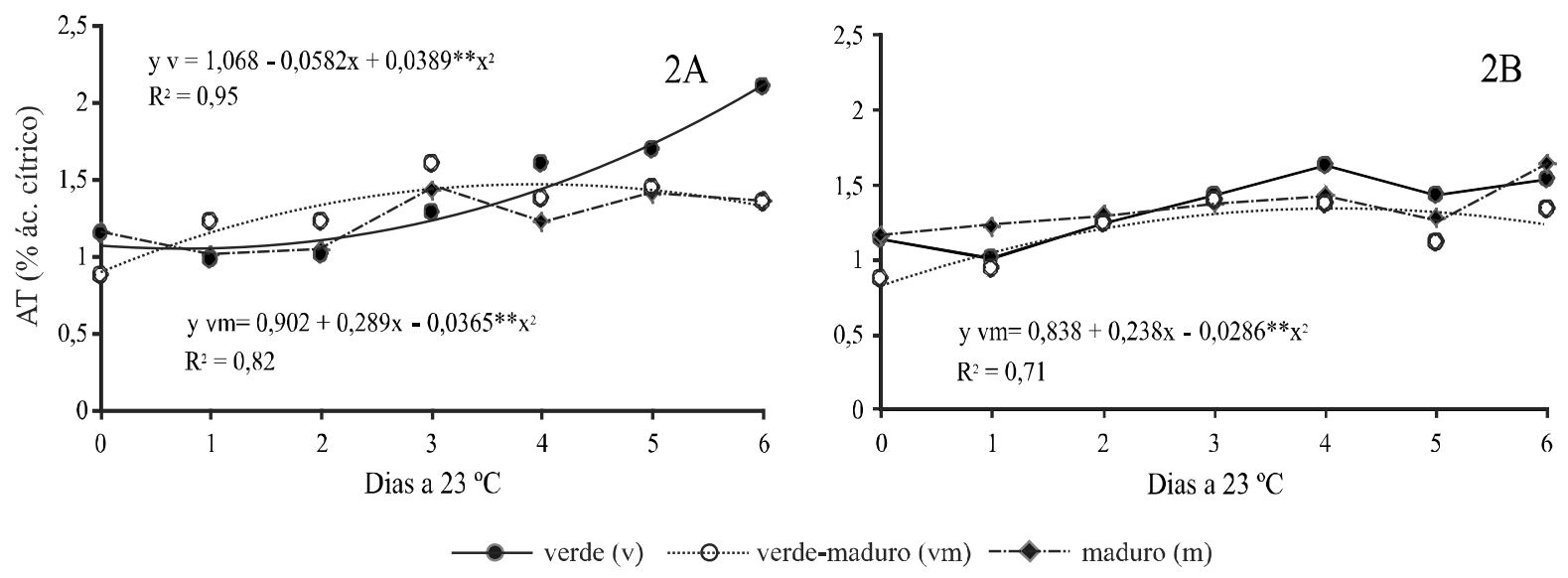

mantidos sob condições ambientes $\left(24{ }^{\circ} \mathrm{C}\right)$ também observou gradativo acréscimo da AT a partir do quarto dia de armazenamento. Dantas Junior (2008) observou valor médio de $1,25 \%$ de AT em frutos de umbuzeiro no estagio 'verde-maduro'. Os valores de AT são similares aos observados por Silva et al. (2011) em frutos de umbuzeiro ligeiramente amarelados.

Em AM, houve um aumento significativo no estádio verde a partir do segundo dia de armazenamento. Em "verde-maduro", a AT teve um aumento gradativo do primeiro ao quarto dia de armazenamento, mantendo este valor até o sexto dia.

De acordo com Chitarra e Chitarra (2005), o teor de ácidos orgânicos, em geral, diminui com a maturação dos frutos, em decorrência do processo respiratório ou de sua conversão em açúcares, sendo que, em alguns casos, como nesse experimento com frutos de umbu, há um pequeno aumento nos valores com o avanço do período. Segundo Raju, Chauhan e Bawa, (2011), o aumento na acidez de produtos armazenados por curtos períodos pode ser, em parte, também explicado pela geração de radicais (ácidos galacturônicos) a partir da hidrólise dos constituintes da parede celular, em especial, as pectinas.

Para a relação SS/AT, foi observada interação significativa entre atmosfera, estádio de maturação e período de armazenamento. A atmosfera de armazenamento de maneira isolada, não influenciou significativamente esta variável.

Em Atmosfera Ambiente (Figura 3A), o estádio 'verde' apresentou os menores valores de SS/AT quando comparados aos estádios 'verde-maduro' e 'maduro'. O aumento da relação SS/AT paralelamente ao amadurecimento de frutos de umbu, também foi observado por Lopes (2007). No estádio verde, ocorreu um decréscimo significativo a partir dos três dias de armazenamento em AA, enquanto que no estádio 'verde-maduro' e maduro a relação SS/AT oscilou durante seis dias de armazenamento.

Frutos armazenados em Atmosfera Modificada (Figura 3B) nos estádios 'verde-maduro' e maduro apresentaram comportamento similar com relação a SS/AT durante o armazenamento, com aumento a partir do primeiro dia e posterior decréscimo. Os menores valores foram encontrados para os frutos no estádio verde quando comparado aos demais, além disso, para este estádio, houve pouca variação de SS/AT durante o armazenamento (Figura 3).

Santos et al. (2010) avaliando características de qualidades em frutos de umbu-cajá obtiveram valor médio de 7,57 para a relação SS/AT. Lima et al. (2002), reportaram consideráveis aumentos da razão SS/AT à medida que os umbu-cajás evoluíam no processo de maturação. Para umbuguela, fruto da mesma espécie, a relação SS/AT também aumentou, atingindo valor máximo de 49,03 no $8^{\circ}$ dia de armazenamento ao ambiente (LIMA NETA, 2008), sendo, entretanto, muito superior à de umbu, conforme observado neste trabalho.

A perda de massa foi significativamente maior para os frutos armazenados em AA e aumentou gradativamente durante o período de armazenamento (Figura 4). Frutos mantidos em AM apresentaram em média $2 \%$ de perda de massa, enquanto que, frutos mantidos em AA (Figura 4A) reduziram aproximadamente em média $9 \%$ de massa fresca. A perda de massa é fortemente reduzida por meio do 
Figura 3 - Relação sólidos solúveis e acidez titulável (SS/AT) em frutos do umbuzeiro nos estádios de maturação 'verde', 'verde-maduro' e 'maduro', durante seis dias de armazenamento a $23 \pm 1^{\circ} \mathrm{C}$ e $83 \pm 2 \%$ UR, sob atmosferas ambiente (3A) e modificada (3B)

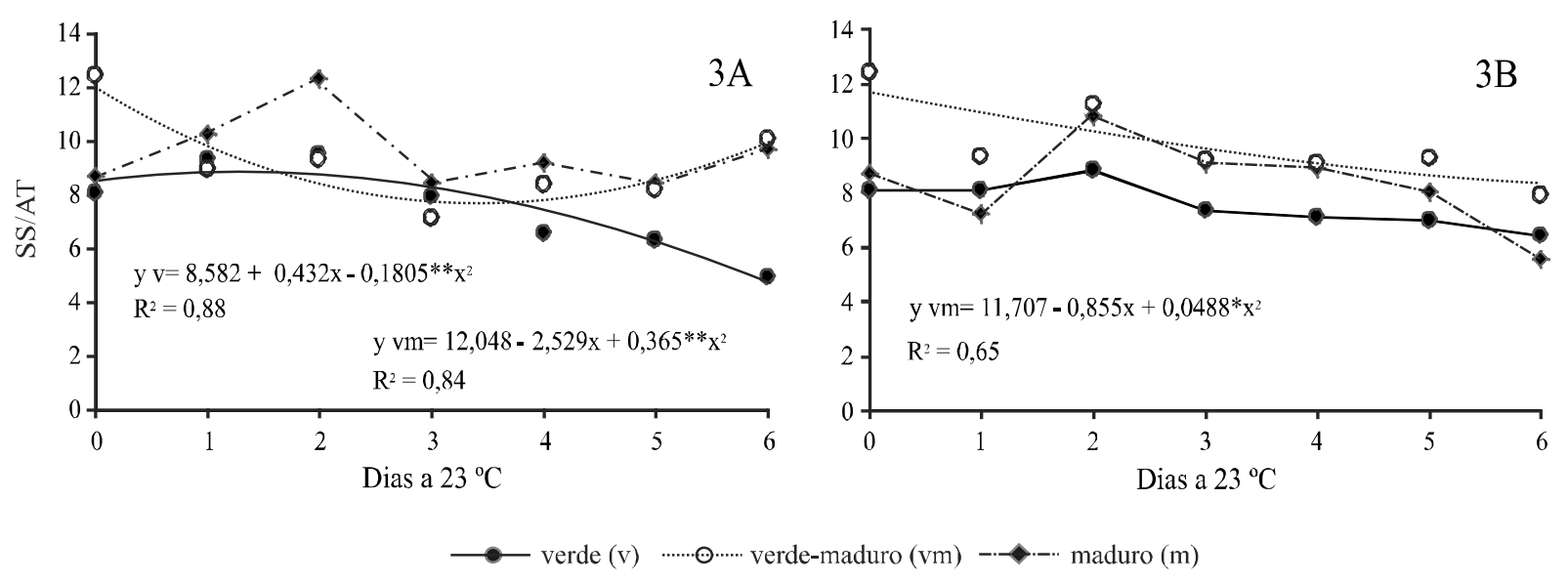

Figura 4 - Perda de massa de frutos de umbuzeiro nos estádios de maturação 'verde', 'verde-maduro' e 'maduro', durante seis dias de armazenamento a $23 \pm 1{ }^{\circ} \mathrm{C}$ e $83 \pm 2 \% \mathrm{UR}$, sob atmosferas ambiente (4A) e modificada (4B)

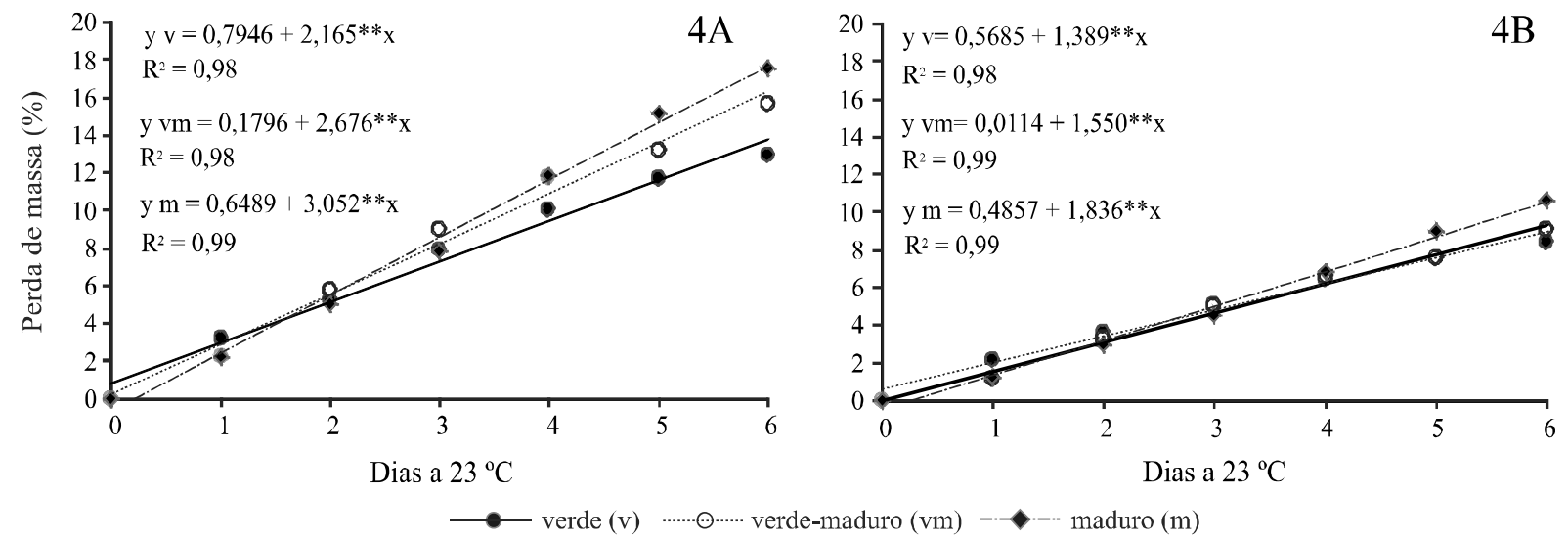

uso de filmes plásticos flexíveis (KADER, 2010), como também foi observado em umbu-laranja (LOPES, 2007) e cajá (FILGUEIRAS, 2001). Esta diferença se deve, principalmente à barreira física representada pelo filme de PVC à perda de água por transpiração, podendo também ser atribuída à redução da concentração de oxigênio e acúmulo de $\mathrm{CO}_{2}$ no interior das embalagens, com consequente redução da taxa de respiração (CHITARRA; CHITARRA, 2005; RAJU; CHAUHAN; BAWA, 2011) e, portanto, da redução da taxa metabólica dos frutos (PALIYATH et al., 2008).

Da mesma forma, a perda de massa foi maior para os frutos no estádio maduros armazenados, tanto em AA quanto em AM, a partir do quarto dia de armazenamento. Em AM, frutos no estádio verde apresentaram perda de massa superior aos demais estádios, sendo que o estádio 'verde-maduro' foi o que apresentou menor perda de massa aos seis dias de armazenamento (Figura 4B).

$\mathrm{O}$ valor de Luminosidade ( $\mathrm{L}^{*}$ ) é um indicador de escurecimento ao longo do armazenamento, que pode ser causado, tanto por reações oxidativas quanto pelo aumento da concentração de pigmentos (KADER, 2010). De maneira geral, os frutos armazenados sob condições de AA (Figura 5A) apresentaram maior luminosidade do que em armazenamento com AM, bem como, o estádio maduro apresentou-se com menos brilho quando comparado com os demais estádios de armazenamento. O estádio 'verde' apresentou aumento significativo com o período de armazenamento em frutos condicionados em AM (Figura 5B). Lopes (2007), avaliando umbu-laranja em condições 
Figura 5 - Luminosidade de frutos do umbuzeiro nos estádios de maturação 'verde', 'verde-maduro' e 'maduro', durante seis dias de armazenamento a $23 \pm 1{ }^{\circ} \mathrm{C}$ e $83 \pm 2 \%$ UR, sob atmosferas ambiente (5A) e modificada (5B)
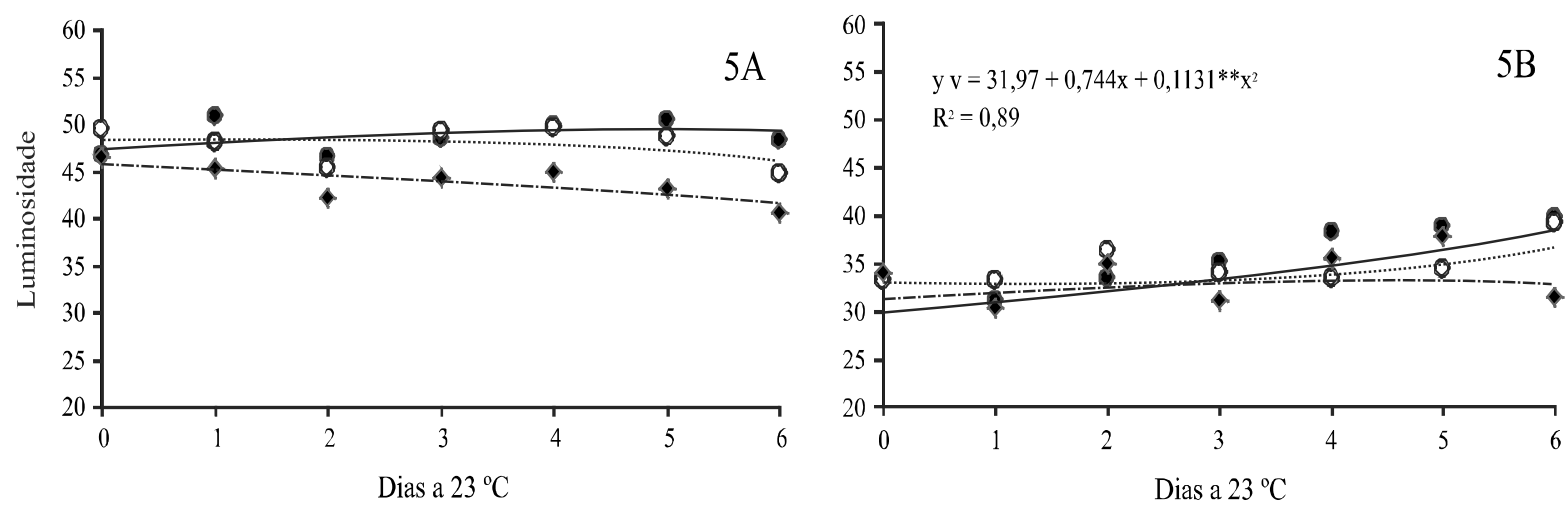

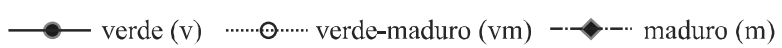

ambiente, observou que independentemente do estádio de maturação estes apresentaram um discreto aumento de luminosidade até o sexto dia de armazenamento.

Para a característica $a^{*}$, foram observadas diferenças significativas para a interação entre período e estádio de maturação. A atmosfera de maneira isolada, não influenciou significativamente esta variável.

A transição da cor verde $\left(-a^{*}\right)$ para o desenvolvimento de uma coloração verde amarelada $\left(+\mathrm{a}^{*}\right)$ foi observada em todos os estádios de maturação ao longo do armazenamento, ou seja, os frutos tenderam a diminuir a intensidade da cor verde mais escuro, mudando o sinal de negativo para positivo no final do armazenamento, para os estádios 'verde-maduro' e maduro. No estádio verde, a cor $\mathrm{a}^{*}$ permaneceu negativa durante todo o armazenamento, mas com aumento gradativo desta característica, conforme pode-se observar na Figura 7, mostrando claramente a evolução do desverdecimento dos frutos durante o armazenamento, como resultado da evolução da maturação. Portanto, com base na evolução da coloração dos frutos deste trabalho verifica-se que umbu pode ser armazenado no estádio 'verde-maduro' e evoluir na maturação em pós-colheita.

A perda da cor verde com o avanço da maturação é característica da maioria dos frutos: ciriguela (MARTINS et al., 2003), cajá (MOURA et al., 2003), mamão (SANCHO et al., 2010), pitanga (SANTOS et al., 2006), umbu (SILVA et al., 2011), entre outros, sendo a cor verde substituída por outros pigmentos de várias tonalidades. De acordo com os pigmentos predominantes e sua distribuição, os frutos apresentam cor de fundo, que corresponde fundamentalmente às clorofilas e carotenóides, nos tons verde, amarelo e alaranjado (CHITARRA; CHITARRA, 2005). Com o avanço da maturação, a coloração verde diminui e aumenta a cor amarela. Isso ocorre em razão da degradação das clorofilas pela ativação das clorofilases e evolução da coloração característica pela biossíntese de pigmentos ou desmascaramento daqueles previamente sintetizados (PALIYATH et al., 2008).

Para a coloração $b^{*}$, foi observada interação significativa para os fatores atmosfera e período de armazenamento. Os frutos sob AA (Figura 6A) mantiveram a tendência de estarem próximos à intensidade da cor amarela durante o armazenamento em relação à intensidade inicial. Já para os frutos sob AM, apesar da diminuição da intensidade da cor amarela ao primeiro dia de armazenamento, esta tendeu a aumentar, consequentemente, a partir do segundo dia apresentando uma maior intensidade da coloração amarela nos frutos (Figura 6B). Estes resultados corroboram com Lopes (2007), que também observou o desverdecimento dos frutos de umbu em diferentes estádios de maturação, sob a condição de temperatura ambiente, e aumento da intensidade amarela pelas características *a e *b, respectivamente. O mesmo ocorreu com umbu 'verde' armazenado sob atmosfera modificada (POLICARPO et al., 2007). Campos (2007) classificou a maturidade de frutos de umbuzeiro com base em diferentes estádios de maturação, segundo a evolução da coloração da casca, observando desde frutos totalmente verdes evoluindo para totalmente amarelos quando maduros.

Verifica-se através da Figura 7A, que os frutos armazenados sob AA apresentaram-se embora que com pouco frescor, moderada perda da turgidez, pouco enrugado, leve perda de brilho, aparência ligeiramente atrativa, ausência de doenças, manchas ou danos externos e/ou podridão, por até seis, cinco e quatro dias 
Figura 6 - Coloração $a^{*}$ e b* de frutos de umbuzeiro nos estágios 'verde', 'verde-maduro' e 'maduro', durante seis dias de armazenamento a $23 \pm 1{ }^{\circ} \mathrm{C}$ e $83 \pm 2 \%$ UR, sob atmosferas ambiente (6A) e modificada (6B)

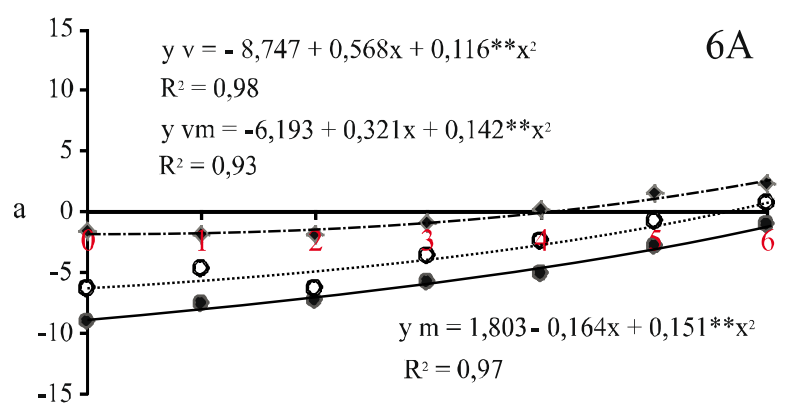

Dias à $23^{\circ} \mathrm{C}$

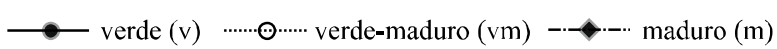

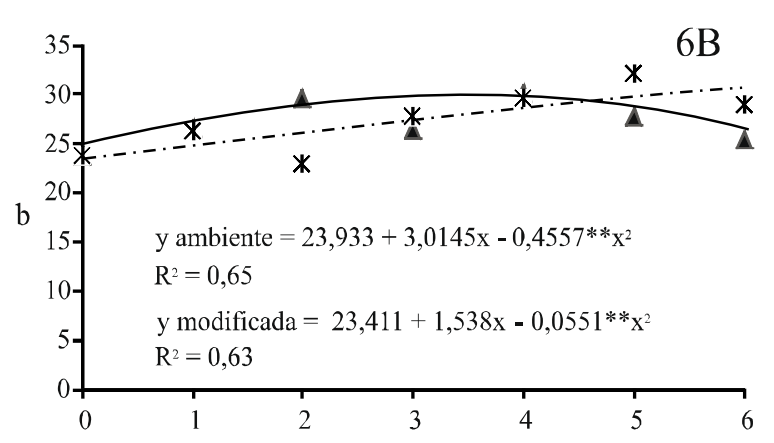

Dias à $23^{\circ} \mathrm{C}$

$\Delta$ ambiente $*$ modificada

Figura 7 - Aparência geral de frutos do umbuzeiro nos estádios de maturação 'verde', 'verde-maduro' e 'maduro', durante seis dias de armazenamento a $23 \pm 1^{\circ} \mathrm{C}$ e $83 \pm 2 \%$ UR, sob atmosferas ambiente (7A) e modificada (7B)

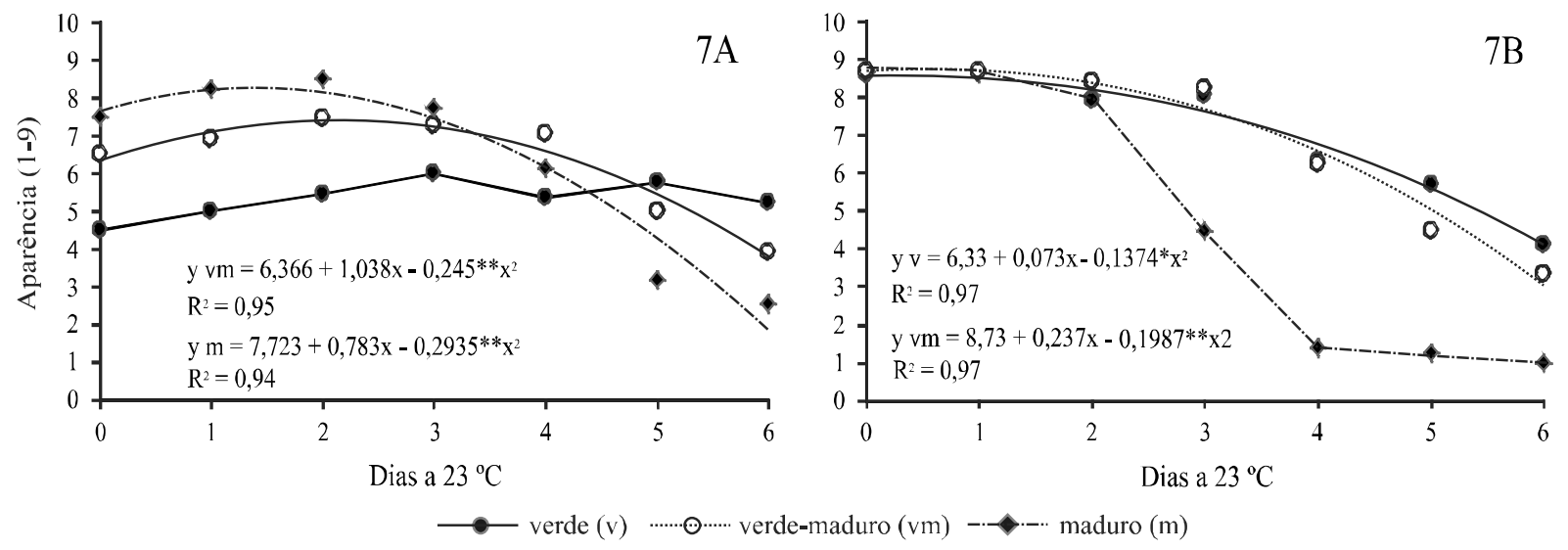

para os estádios 'verde', 'verde-maduro' e 'maduro', respectivamente, mas ainda com além da aparência geral aceitável pelos consumidores. Quando mantidos sob AM, os frutos de umbuzeiro foram caracterizados em aceitáveis em aparência geral por até cinco dias no estádio verde e quatro dias para o estádio 'verde-maduro'. No entanto, quando analisado o estádio 'maduro', percebe-se uma queda brusca na aparência geral a partir do 2 dia de armazenamento, permanecendo aceitáveis por até três dias (Figura 7B). Neste caso, os frutos apresentaram inicialmente incidência de podridão, provavelmente devido à exudação do conteúdo da polpa em decorrência da fragilidade da epiderme, causada pela própria transpiração do fruto, sendo adicionalmente favorecida pela elevada temperatura de armazenamento $\left(23 \pm 1^{\circ} \mathrm{C}\right)$.

Aos seis dias de armazenamento, os frutos no estádio maduro se encontravam com murchamento acentuado, superfície enrugada e murcha em quase $50 \%$ da amostra, sem brilho aparente e danos externos e/ ou podridão, sobretudo aqueles mantidos sob AA.

Nos próximos estudos, a utilização de refrigeração associada à atmosfera modificada deve ser avaliada como uma ferramenta para ampliar a vida útil pós-colheita de umbu, sobretudo para frutos colhidos no estádio de maturação 'verde-maduro', de modo a agregar valor e ampliar as possibilidades de comercialização e consumo desse fruto.

\section{CONCLUSÕES}

1. O estádio de maturação na colheita dos frutos do umbuzeiro é fator determinante na conservação da qualidade pós-colheita; 
2. O uso da atmosfera modificada utilizando-se filme de PVC (14 $\mu \mathrm{m}$ de espessura) reduz notadamente a perda de massa de umbu, nos três estádios de maturação durante seis dias de armazenamento a $23 \pm 1{ }^{\circ} \mathrm{C}$;

3. O armazenamento do umbu sob atmosfera ambiente limita a sua vida útil pós-colheita a três dias.

\section{REFERÊNCIAS}

ALMEIDA, M. M. B. et al. Bioactive compounds and antioxidant activity of fresh exotic fruits from Northeastern Brazil. Food Research International, v. 44, n. 7, p. 21552159, 2011.

ALVES, R. E. et al. Postharvest physiology and biochemistry of some non-traditional American Tropical Fruits. Acta Horticulturae, v. 768, p. 233-238, 2008.

BORGES, S. V. et al. Efeito de aditivos sobre a cor durante o armazenamento de doces de umbu (Spondias tuberosa Arr. Câmera) verde e maduro. Alimentos e Nutrição, v. 22, n. 2, p. 307-313, 2011.

CAMPOS, C. O. Frutos de umbuzeiro (Spondias tuberosa Arruda): características físico-químicas durante seu desenvolvimento e na pós-colheita. 2007. 113 f. Tese (Doutorado em Agronomia) - Universidade Estadual Paulista, Faculdade de Ciências Agronômicas, Botucatu, 2007.

Chitarra, M. I. F.; Chitarra, A. B. Pós-colheita de frutas e hortaliças: fisiologia e manuseio. 2. ed. Lavras: UFLA, 2005. $543 \mathrm{p}$.

DANTAS JUNIOR, O. R. Qualidade e capacidade antioxidante total de frutos de genótipos de umbuzeiro oriundos do semi-árido nordestino. 2008. 90 f. Tese (Doutorado em Agronomia) - Centro de Ciências Agrárias, Universidade Federal da Paraíba, Areia, 2008.

DUQUE, G. O Nordeste e as lavouras xerófilas. 4. Ed. Banco do Nordeste do Brasil. Fortaleza, 2004. 236 p.

FILGUEIRAS, H. A. C. Geração de técnicas de conservação pós-colheita para valorização do cultivo de cajá e ciriguela no Estado do Ceará. Fortaleza: Embrapa Agroindústria Tropical, 2001. 47 p.

INSTITUTOBRASILEIRODE GEOGRAFIAEESTATÍSTICA. Produtos das lavouras permanentes. 2010. Disponível em: <http://www.ibge.gov.br/home/estatistica/economia/pevs/2010/ tabelas_pdf/tab01.pdf >. Acesso em: 10 jan. 2012.

INSTITUTO ADOLFO LUTZ. Normas analíticas do Instituto Adolfo Lutz: Métodos físico-químicos para análise de alimentos. 4. ed.São Paulo, 2008. 1020 p.

KADER, A. A. Future of Modified Atmosphere Research. Acta Horticulturae, v. 857, p. 212-217, 2010.

KAFKAS, E. et al. Quality characteristics of strawberry genotypes at different maturation stages. Food Chemistry. v. 100, n. 3, p. 1229-1236, 2007.
LIMA, E. D. P. A. et al. Caracterização física e química dos frutos da umbu-cajazeira (Spondias spp.) em cinco estádios de maturação, da polpa e néctar. Revista Brasileira de Fruticultura, v. 24, n. 2, p. 338-343, 2002.

LIMA NETA, A. de O. Aspectos da fisiologia da maturação e qualidade de frutos da umbugueleira (Spondias sp.). 2008. 50 f. Monografia (Graduação em Agronomia) - Centro de Ciências Agrárias, Universidade Federal da Paraíba, Areia, 2008.

LOPES, M. F. Fisiologia da Maturação e Conservação PósColheita do Acesso Umbu- Laranja (Spondias tuberosa Arruda Câmara). João Pessoa. CT/UFPB, 2007. 123p. (Dissertação de Mestrado, Programa de Pós-Graduação em Ciência e Tecnologia de Alimentos).

LORENZI, H. Árvores brasileiras: Manual de identificação e cultivo de plantas arbóreas nativas do Brasil. 3. ed. Nova Odessa, SP: Instituto Plantarum, 2000. 368 p. v. 1.

MARTINS, L. P. et al. Desenvolvimento de frutos de cirigueleira (Spondias purpurea L.). Revista Brasileira de Fruticultura, v. 25, n. 1 , p. 11-14, 2003.

MARTINS, M. L. A. et al. Características de doce em massa de umbu verde e maduro e aceitação pelos consumidores. Pesquisa Agropecuária Brasileira, v. 42, n. 9, p. 1329-1333, 2007.

MATTIETTO, R. A.; LOPES, A. S.; MENEZES, H. C. Estabilidade do néctar misto de cajá e umbu. Ciência e Tecnologia de Alimentos, v. 27, n. 3, p. 453-463, 2007.

MOURA, F. T. et al. Evolução do Crescimento e da Maturação de Frutos de Cajazeira (Spondias mombin L). Proceedings of The Interamerican Society for Tropical Horticulture, v, 47, p. 231-233, 2003.

NARAIN, N. et al. Variation in physical and chemical composition during maturation of umbu (Spondias tuberosa). Food Chemistry, v. 44, p. 255-259, 1992.

PALIYATH, G. et al. Postharvest biology and technology of fruit, vegetables, and flowers. Ames: Wiley-Blackwell, 2008. 497 p.

POLICARPO, V. M. N. et al. Green umbu (Spondias tuberosa arr. cam.) preserve: physical, chemical and microbiological changes during storage. Journal of Food Processing and Preservation, v. 31, n. 2, p. 201-210, 2007.

RAJU, P. S.; CHAUHAN, O. P.; BAWA, A. S. Handbook of Vegetables and Vegetable Processing: Postharvest Handling Systems and Storage of Vegetables. Iowa: Blackwell Publishing Ltd, 2011. 772 p.

RUFINO, M. do S. M. et al. Bioactive compounds and antioxidant capacities of 18 non-traditional tropical fruits from Brazil. Food Chemistry, v. 121, n. 4, p. 996-1002, 2010.

SANCHO, E. G. G. et al. Effect of maturity stage of papaya maradol on physiological and biochemical parameters. American Journal of Agricultural and Biological Sciences, v. 5, n. 2, p. 194-203, 2010.

SANTOS, M. B. et al. Caracterização e qualidade de frutos de umbu-cajá (Spondias tuberosa x s. mombin) provenientes do recôncavo Sul da Bahia. Revista Brasileira Fruticultura, v. 32, n. 4, p. 1089-1097, 2010. 
SANTOS, A. F. et al. Armazenamento de pitangas sob atmosfera modificada e refrigeração: II - qualidade e conservação pós-colheita. Revista Brasileira Fruticultura, v. 28 , n. 1 , p. $42-45,2006$.

SANTOS, C. A. F.; RODRIGUES, M. A.; ZUCCHI, M. I. Variabilidade genética do umbuzeiro no Semi-Árido brasileiro, por meio de marcadores AFLP. Pesquisa Agropecuária Brasileira, v. 43, n. 8, p. 1037-1043, 2008.

SILVA, S. M. et al. Quality During Maturation of OrangeUmbu (Spondias tuberosa Arr. Cam.) from Paraíba State Semi-Arid, Brazil. Acta Horticulturae, v. 894, p. 231-237, 2011.
SILVA, F. V. G. et al. Bioactive compounds and antioxidant activity in fruits of clone and ungrafted genotypes of yellow mombin tree. Ciência e Tecnologia de Alimentos, v. 32, n. 4, p. 639-646, 2012.

SOUZA, F. X. de. Spondias agroindustriais e os seus métodos de propagação. Fortaleza: EMBRAPA, 1998. 28 p.

TIBURSKI, J. H. et al. Nutritional properties of yellow mombin (Spondias mombin L.) pulp. Food Rosearch International, v. 44, n. 7, p. 2326-2331, 2011.

TURINI, E. Umbu (fruto). Companhia Nacional de Abastecimento, 2010. Disponível em: <http://www.conab. gov.br/.../11_06_30_17_46_37_umbu junho.pdf. Acesso em: 8 ago. 2010. 